\title{
Artisan Aphakic Lens for Cataract Surgery in Anterior Megalophthalmos
}

\author{
Virgilio Galvis $^{\mathrm{a}-\mathrm{c}}$ Alejandro Tello ${ }^{\mathrm{a}-\mathrm{c}}$ Giuseppe Miotto ${ }^{\mathrm{a}}$ \\ Carlos M. Rangel ${ }^{b}$ \\ ${ }^{a}$ Centro Oftalmológico Virgilio Galvis, and ${ }^{\mathrm{b}}$ Fundación Oftalmológica de \\ Santander/Clinica Ardila Lulle (FOSCAL), Floridablanca, and \\ 'Universidad Autónoma de Bucaramanga (UNAB), Bucaramanga, Colombia
}

\section{Key Words}

Iris-claw intraocular lens $\cdot$ Megalocornea $\cdot$ Megalophthalmos

\begin{abstract}
A 44-year-old man with anterior megalophthalmos arrived at the clinic presenting a cataract in the right eye. The corneal diameter was $13 \mathrm{~mm}$. Iridodonesis and phacodonesis were evident during slit lamp examination. Anterior chamber depth was $5.89 \mathrm{~mm}$, and the diameter of the capsular bag was approximately $14.45 \mathrm{~mm}$. Due to the large capsular bag, a standard posterior chamber intraocular lens was considered inadequate because of potential instability. Phacoemulsification and an implantation of an iris-claw lens (Artisan for aphakia ${ }^{\circledR}$, Ophtec) in the posterior chamber were performed with good results. In the fourth postoperative month, uncorrected distance visual acuity was 20/30, and 20/20 was achieved with $+0.75-1.25 \times 10^{\circ}$. We consider retropupillary aphakic iris-claw intraocular lenses to be a worthwhile option in these cases of megalophthalmos and cataract, since instability is avoided and the procedure is less challenging than suturing the lens.
\end{abstract}

\section{Introduction}

Seefelder initially described anterior megalophthalmos in 1914, as cited by Wright [1]. It is characterized by megalocornea which is associated with a very deep anterior chamber and ciliary ring elongation [1]. It is also known as X-linked megalocornea since it is almost always an X-linked recessive condition [2]. Frequently, it is accompanied by the early development of cataracts and zonular anomalies $[1,2]$. Cataract surgery involves the risk of subluxation of the cataract as a result of zonular weakness. In addition, there is a risk of a standard intraocular lens (IOL) decentration if the IOL is implanted in the sulcus or capsular bag, because of their large diameters. Cataract surgeons must be aware of these unique circumstances when performing surgery on these cases. Treatments such as the implantation of a retropupillary irisclaw aphakic intraocular lens may yield better outcomes. 


\section{Case Report}

A 44-year-old man presented complaining of reduced visual acuity in his right eye. Uncorrected visual acuity (UCVA) in the right eye was $20 / 400$ and best corrected visual acuity (BCVA) was 20/200, with a refraction of plano $-2.00 \times 10^{\circ}$. In the left eye, UCVA was $20 / 80$ and BCVA $20 / 25$ with a refraction of $+1.50-3.00 \times 0^{\circ}$. Upon examination, both eyes showed evidence of megalocornea, with a corneal diameter of $13 \mathrm{~mm}$, mild endothelial pigment, very deep anterior chambers, wide-open angles with pigment, iridodonesis, and phacodonesis. No iris transillumination defects were visible. In the right eye, there was posterior subcapsular opacity, in addition to a nuclear and cortical cataract with evidence of one quadrant zonular dialysis ( $\underline{\text { fig. 1 }}$ ). In the left eye, an incipient cortical and nuclear cataract was observed. Intraocular pressure was $10 \mathrm{~mm} \mathrm{Hg}$ in both eyes. The cup-to-disc ratio was 0.2 in both eyes, and the retina was within normal limits.

Additional tests were performed in the right eye. The results were: ultrasonic pachymetry, 508 $\mu \mathrm{m}$, endothelial cell count, 2,183 cells $/ \mathrm{mm}^{2}$, and axial length by partial coherence interferometry (IOL Master), $24.59 \mathrm{~mm}$. Corneal tomography (Orbscan IIz) showed no signs of ectasia (Sim K $43.5 \times$ $46.0 \mathrm{D})$. The anterior chamber depth measured by IOL Master was $5.89 \mathrm{~mm}$. The diameter of the capsular bag by Visante OCT was approximately $14.45 \mathrm{~mm}$ (fig. 1).

Anterior megalophthalmos and cataract were diagnosed. We decided to perform phacoemulsification with implantation of an iris-claw lens (Artisan for aphakia ${ }^{\circledR}$, Ophtec) in the posterior chamber. The calculation of intraocular lens power for emmetropia with our personalized A-constant for retropupillary iris-claw lens (117.5) was $+18.00 \mathrm{D}$ using the Haigis formula. Cataract phacoemulsification (divide and conquer), which was difficult technically because of the extreme depth of the anterior chamber, was performed by one of the authors using topical anesthesia (V.G.). The incision was widened to $6 \mathrm{~mm}$ (between 11 and 12:30 clock hours) and an aphakia Artisan ${ }^{\circledR}$ was fixed, upside down, to the posterior surface of the iris, leaving the posterior capsule untouched. The superior incision was closed with 3 interrupted sutures (fig. 1).

In the fourth postoperative month, uncorrected distance visual acuity was 20/30, and 20/20 was achieved with $+0.75-1.25 \times 10^{\circ}$. The patient was very satisfied with the results.

\section{Discussion}

In patients with corneal enlargement or evident bulging of the cornea, differential diagnoses include the following: megalocornea/megalophthalmos [1-19], congenital glaucoma and keratoglobus [3]. Megalocornea may present as simple isolated megalocornea with no additional ocular signs, or as anterior megalophthalmos, in which there are abnormalities of other anterior segment structures in addition to the cornea. The anterior chamber is very deep, and frequently, the ciliary ring and the capsular bag are enlarged [1-19]. Often, however, it seems that authors have had difficulty determining a clear line between the two conditions in published literature, and anterior megalophthalmos cases have been deemed megalocorneas $[8,10,12,15-$ $17,19]$. It is always necessary to rule out glaucoma by measuring the intraocular pressure. Corneal enlargement in congenital glaucoma is usually progressive and asymmetric. Frequently, symptoms like photophobia and tearing are present, along with a characteristic sign: horizontal or radial breaks in Descemet's membrane, which may be single or multiple (Haab's striae). Although usually symmetric, corneal enlargement in megalocornea/megalophthalmos may be asymmetric [3]. While in congenital or infantile glaucoma the axial length is elongated mostly due to an expansion of the posterior segment, in megalocornea/megalophthalmos the anterior chamber is enlarged at the expense of the posterior segment [2]. In megalocornea/ megalophthalmos posterior bowing of the iris is often, but not always, associated with iris transillumination, which is not seen in glaucoma. Keratoglobus is a corneal ectasia 
that causes, like megalocornea/megalophthalmos, bilateral bulging globoid corneas. Unlike megalocornea/megalophthalmos, where the corneas show normal curvature [4$9,11,12,16,18]$ and normal or mildly decreased thickness $[4,6,8,14,16]$, in keratoglobus they are remarkably thin, and the enlargement of the corneal diameter is small [3].

In table 1 we summarize the published cases of cataract extraction and IOL placement in patients with anterior megalophthalmos since 1984 [4-19]. As shown, different approaches have been used to avoid intraocular lens instability, including larger custom-made IOLs $[5,14]$ and IOL suturing techniques $[4,6,9,10]$. It has been published that in the long term, iris sutured IOLs may become loose in these eyes with anterior megalophthalmos [17]. When aphakic iris-claw lenses, currently known as Artisan ${ }^{\circledast}$ (Ophtec) or Verisyse ${ }^{\circledast}$ (Abbott Medical Optics Inc.), became more easily available in a wider range of countries, surgeons began using them in cases of anterior megalophthalmos by implanting them in the anterior $[12,17]$ or posterior chambers [13]. In agreement with other authors [12, 13, 17], we believe that this type of lens is an excellent alternative for patients with anterior megalophthalmos and cataract. These lenses eliminate the difficulties associated with instability of standard lenses within an enlarged bag or ciliary sulcus [5, 7-9, 15] or in an enlarged anterior chamber [7]. Furthermore, the technique is easier and faster than suturing an IOL to the iris $[4,6,9$, 10]. Oetting and Newsom [12] implanted aphakic iris-claw lenses in the anterior chambers of two eyes in late secondary procedures. Lee et al. [13] fixed the lenses retropupillary in two eyes, according to the technique originally described by Rijneveld et al. [20] and then by Mohr et al. [21]. Both techniques, fixation in the anterior and posterior surfaces of the iris, have showed satisfactory results in the published cases of anterior megalophthalmos; however, refixation of the lens was required in one eye where the lens was placed in the anterior chamber [12]. Before operating on this patient, we found the description of Lee et al. [13] and considered the posterior chamber implantation of the iris-claw lens to be a very strong option. As such, similar to Lee et al. [13], we employed the retropupillary fixation technique, but unlike them, we performed the procedure using topical anesthesia. Other differences with Lee et al. [13] included that we made a superior incision, not a temporal one, and used a spatula, not enclavation needles as they did, for IOL fixation in the posterior surface of the iris through paracentesis incisions performed at the 3 and 9 o'clock positions. Using the superior incision and two side port entries, we avoided more inferior incisions, which may have a higher risk of anterior chamber contamination given the possibility that microorganisms could accumulate in the inferior tear lake that is in contact with an inferior side port site [22]. Usage of a spatula might make the enclavation step easier. In fact, in other retropupillary fixated aphakic iris-claw IOLs we have used a long spatula or a Bechert nucleus rotator to fixate both haptics entering through only one paracentesis, so that the surgeon does not have to switch hands during the maneuver.

\section{Disclosure Statement}

This work did not receive financial support from any source. The authors do not have any interests in the products mentioned in this article. 
Table 1. Reported cases of cataract surgery and IOL implantation in anterior megalophthalmos

\begin{tabular}{|c|c|c|}
\hline First author, year & Case/eye & Surgical technique/IOL \\
\hline \multirow[t]{2}{*}{$\begin{array}{l}\text { Neumann, } \\
1984[4]\end{array}$} & $\begin{array}{l}\text { Case 1: OU } \\
\text { (Neumann, 1984) }\end{array}$ & $\begin{array}{l}\text { ECCE + IOL in sulcus: decentration. It was removed and a Medallion IOL } \\
\text { sutured to iris. In the fellow eye: Medallion IOL sutured to iris }\end{array}$ \\
\hline & Case 2 (Neumann, 1984) & ECCE + Medallion IOL sutured to iris \\
\hline \multirow[t]{2}{*}{$\begin{array}{l}\text { Kwitko, } \\
1991[5]\end{array}$} & Case 1: OU (Kwitko, 1991) & $\begin{array}{l}\text { OD: ECCE + IOL }(14 \mathrm{~mm}) \text { in sulcus. } 6 \text { months POP: mild inferior } \\
\text { decentration. } 1 \text { year POP: retinal detachment. OS: ECCE + IOL }(14 \mathrm{~mm}) \text { in } \\
\text { sulcus. } 1 \text { year POP: mild superior decentration. } 18 \text { months POP: retinal } \\
\text { detachment. Following retinopexy, IOL subluxation }\end{array}$ \\
\hline & Case 2: OD (Kwitko, 1991) & OD: ECCE + IOL (18 mm). Good evolution \\
\hline Dua, 1999 [6] & Case 1: OU (Dua, 1999) & OU: ECCE + IOL sutured to iris and anterior capsule \\
\hline \multirow[t]{4}{*}{ Javadi, 2000 [7] } & Case 1: OU (Javadi, 2000) & OU: ECCE + standard IOL in the bag \\
\hline & Case 2: OU (Javadi, 2000) & $\begin{array}{l}\text { OD: ECCE + standard IOL in the bag (can-opener capsulotomy). } \\
\text { Decentration. OS: ECCE+ standard IOL in the bag }\end{array}$ \\
\hline & Case 3: OD (Javadi, 2000) & $\begin{array}{l}\text { OD: ECC + LIO. Zonular dialysis, anterior vitrectomy and AC IOL. Significant } \\
\text { pseudophacodonesis. Retinal detachment } 3 \text { months POP }\end{array}$ \\
\hline & Case 4: OS (Javadi, 2000) & OS: phacoemulsification + standard IOL in the bag. Zonular dialysis \\
\hline $\begin{array}{l}\text { de Sanctis, } \\
2004[8]\end{array}$ & $\begin{array}{l}\text { Case 1: OU (de Sanctis, } \\
\text { 2004) }\end{array}$ & $\begin{array}{l}\text { OD: phacoemulsification + foldable IOL + capsular tension ring. Zonular } \\
\text { dialysis. Mild superior decentration. OS: phacoemulsification + foldable IOL }\end{array}$ \\
\hline \multirow[t]{3}{*}{ Sharan, 2005 [9] } & Case 1: OU (Sharan, 2005) & $\begin{array}{l}\text { OD: ECCE + aphakia. OS: ECCE + aphakia. } 10 \text { years later secondary } \\
\text { implantation: sutured AC IOL }\end{array}$ \\
\hline & Case 2: OU (Sharan, 2005) & $\begin{array}{l}\text { OD: ECCE + aphakia. OS: ECCE + aphakia. } 1 \text { year later secondary } \\
\text { implantation standard IOL: decentration. Explantation and iris sutured IOL }\end{array}$ \\
\hline & Case 3: OU (Sharan, 2005) & $\begin{array}{l}\text { OD: ECCE + aphakia. Secondary implantation: IOL }(14 \mathrm{~mm}) . \text { OS: ECCE + IOL } \\
(14 \mathrm{~mm})\end{array}$ \\
\hline Basti, 2005 [10] & Case 1: OD (Basti, 2005) & $\begin{array}{l}\text { OD: sutured AC IOL. Decentration, instability. Explantation, and } \\
\text { implantation of a posterior chamber IOL sutured to iris }\end{array}$ \\
\hline Tsai, 2005 [11] & Case 1: OD (Tsai, 2005) & OD: phacoemulsification + standard IOL in the bag \\
\hline Oetting, 2006 [12] & Case 1:0U (Oetting, 2006) & $\begin{array}{l}\text { OU: intracapsular extraction, aphakia. Late secondary implantation (20 } \\
\text { years POP): iris-claw IOLs in AC. Refixation was required in OD }\end{array}$ \\
\hline Lee, 2006 [13] & Case 1: OU (Lee, 2006) & $\begin{array}{l}\text { OS: pigmentary glaucoma. Previous trabeculectomy. Phacoemulsification + } \\
\text { retropupillary iris-claw IOL. OD: phacoemulsification + retropupillary iris- } \\
\text { claw IOL }\end{array}$ \\
\hline Vaz, 2007 [14] & Case 1: OU (Vaz, 2007) & OU: phacoemulsification + custom-made IOL $(16 \mathrm{~mm})$ in the bag \\
\hline $\begin{array}{l}\text { Berry-Brincat, } \\
2008[15]\end{array}$ & $\begin{array}{l}\text { Case 1: OU } \\
\text { (Berry-Brincat, 2008) }\end{array}$ & OU: phacoemulsification + 3-piece foldable IOL in the bag. Decentration \\
\hline Assia, 2009 [16] & Case 1: OU (Assia, 2009) & $\begin{array}{l}\text { OU: phacoemulsification + } 3 \text {-piece foldable IOL in the bag. OD: scleral } \\
\text { wound leak requiring resuturing. Both eyes: hyperopic result (SRK/T } \\
\text { formula was used) }\end{array}$ \\
\hline $\begin{array}{l}\text { Welder, } \\
2010[17]\end{array}$ & Case 1:OU (Welder, 2010) & $\begin{array}{l}\text { OU: iris sutured IOLs. OS: late instability, explantation and iris-claw IOL in } \\
\text { AC }\end{array}$ \\
\hline Zare, 2011 [18] & Case 1: OS (Zare, 2011) & OS: phacoemulsification + standard IOL in the bag \\
\hline Rękas, 2011 [19] & Case 1: OU & OU: phacoemulsification + foldable IOL sutured to a capsular tension ring \\
\hline $\begin{array}{l}\text { Galvis, } 2012 \\
\text { (present case } \\
\text { report) }\end{array}$ & Case 1: OD & OD: phacoemulsification + retropupillary iris-claw IOL \\
\hline
\end{tabular}



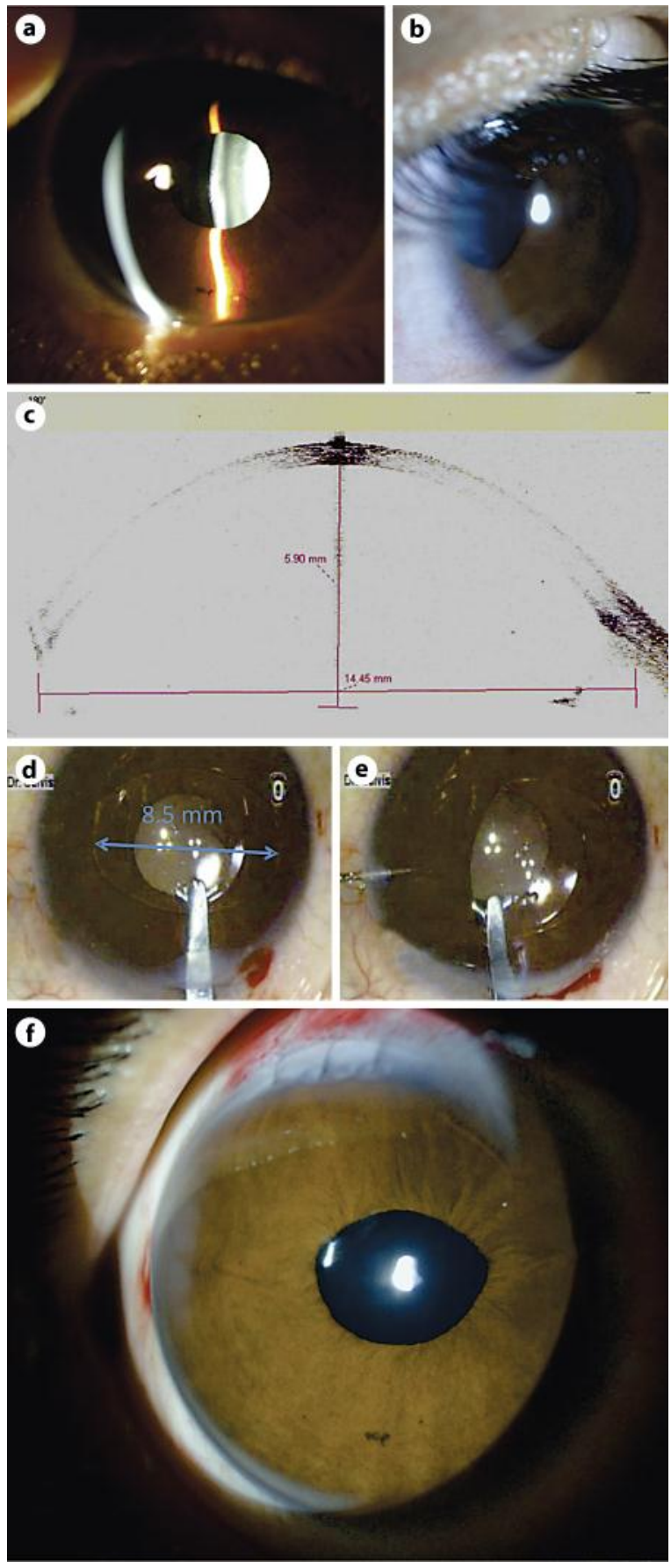

Fig. 1. a, b Slit lamp examination: megalocornea, very deep anterior chamber and cataract. c Visante OCT. $\mathbf{d}$ Artisan aphakic IOL in the anterior chamber. e Enclavation of the first IOL haptic in the posterior iris. $\mathbf{f}$ Appearance on first postoperative day. 


\section{References}

1 Wright RE: Megalophthalmus and microphthalmus. Br J Ophthalmol 1922;6:35-37.

-2 Meire FM, Delleman JW: Biometry in X linked megalocornea: pathognomonic findings. Br J Ophthalmol 1994;78:781-785.

3 Ho CL, Walton DS: Primary megalocornea: clinical features for differentiation from infantile glaucoma. J Pediatr Ophthalmol Strabismus 2004;41:11-17; quiz 46-47.

-4 Neumann AC: Anterior megalophthalmos and intraocular lens implantation. J Am Intraocul Implant Soc 1984;10:220-222.

-5 Kwitko S, Belfort Júnior R, Omi CA: Intraocular lens implantation in anterior megalophthalmus. Case report. Cornea 1991;10:539-541.

-6 Dua HS, Azuara-Blanco A, Pillai CT: Cataract extraction and intraocular lens implantation in anterior megalophthalmos. J Cataract Refract Surg 1999;25:716-719.

7 Javadi MA, Jafarinasab MR, Mirdehghan SA: Cataract surgery and intraocular lens implantation in anterior megalophthalmos. J Cataract Refract Surg 2000;26:1687-1690.

-8 de Sanctis U, Grignolo FM: Cataract extraction in X-linked megalocornea: a case report. Cornea 2004;23:533-535.

-9 Sharan S, Billson FA: Anterior megalophthalmos in a family with 3 female siblings. J Cataract Refract Surg 2005;31:1433-1436.

10 Basti S, Koch DD: Secondary peripheral iris suture fixation of an acrylic IOL in megalocornea. J Cataract Refract Surg 2005;31:7; author reply 8.

11 Tsai CK, Lai IC, Kuo HK, Teng MC, Fang PC: Anterior megalophthalmos. Chang Gung Med J 2005;28:191195.

12 Oetting TA, Newsom TH: Bilateral Artisan lens for aphakia and megalocornea: long-term follow-up. J Cataract Refract Surg 2006;32:526-528.

13 Lee G, Hann J, Braga-Mele R: Phacoemulsification in anterior megalophthalmos. J Cataract Refract Surg 2006;32:1081-1084.

14 Vaz FM, Osher RH: Cataract surgery and anterior megalophthalmos: custom intraocular lens and special considerations. J Cataract Refract Surg 2007;33:2147-2150.

15 Berry-Brincat A, Chan TK: Megalocornea and bilateral developmental cataracts. J Cataract Refract Surg 2008;34:168-170.

16 Assia EI, Segev F, Michaeli A: Cataract surgery in megalocornea: comparison of 2 surgical approaches in a single patient. J Cataract Refract Surg 2009;35:2042-2046.

17 Welder J, Oetting TA: Megalocornea. EyeRounds.org. Sept. 16, 2010; available from: http://www.EyeRounds.org/cases/121-megalocornea.htm. Accessed October 19, 2012.

18 Zare MA, Eshraghi B, Kiarudi MY, Masoule EA: Application of ultrasound biomicroscopy in the planning of cataract surgery in anterior megalophthalmos. Indian J Ophthalmol 2011;59:400-402.

19 Rękas M, Pawlik R, Kluś A, Różycki R, Szaflik JP, Ołdak M: Phacoemulsification with corneal astigmatism correction with the use of a toric intraocular lens in a case of megalocornea. J Cataract Refract Surg 2011;37:1546-1550.

20 Rijneveld WJ, Beekhuis WH, Hassman EF, Dellaert MM, Geerards AJ: Iris claw lens: anterior and posterior iris surface fixation in the absence of capsular support during penetrating keratoplasty. J Refract Corneal Surg 1994;10:14-19.

21 Mohr A, Hengerer F, Eckardt C: Retropupillary fixation of the iris claw lens in aphakia. 1 year outcome of a new implantation technique. Ophthalmologe 2002;99:580-583.

-22 Miller JJ, Scott IU, Flynn HW Jr, Smiddy WE, Newton J, Miller D: Acute-onset endophthalmitis after cataract surgery (2000-2004): incidence, clinical settings, and visual acuity outcomes after treatment. Am J Ophthalmol 2005;139:983-987. 